\title{
Immunological and genetic kinetics from diagnosis to clinical progression in chronic lymphocytic leukemia
}

Isabel Jiménez ${ }^{1,2}$, Bárbara Tazón-Vega ${ }^{2,3}$, Pau Abrisqueta ${ }^{2,3}$, Juan C. Nieto ${ }^{1,2}$, Sabela Bobillo2,3,

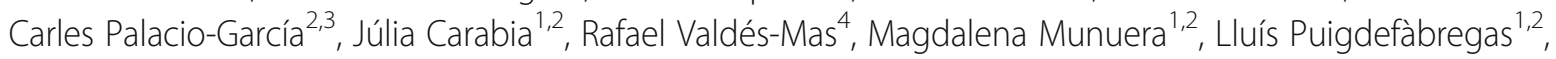
Genís Parra ${ }^{5,6}$, Anna Esteve-Codina ${ }^{5,6}$, Clara Franco-Jarava7, Gloria lacoboni ${ }^{2,3}$, María José Terol ${ }^{8}$, José Antonio García-Marco ${ }^{9}$, Marta Crespo ${ }^{1,2+}$ and Francesc Bosch ${ }^{2,3^{*+}}$ (i)

\begin{abstract}
Background: Mechanisms driving the progression of chronic lymphocytic leukemia (CLL) from its early stages are not fully understood. The acquisition of molecular changes at the time of progression has been observed in a small fraction of patients, suggesting that CLL progression is not mainly driven by dynamic clonal evolution. In order to shed light on mechanisms that lead to CLL progression, we investigated longitudinal changes in both the genetic and immunological scenarios.

Methods: We performed genetic and immunological longitudinal analysis using paired primary samples from untreated CLL patients that underwent clinical progression (sampling at diagnosis and progression) and from patients with stable disease (sampling at diagnosis and at long-term asymptomatic follow-up).

Results: Molecular analysis showed limited and non-recurrent molecular changes at progression, indicating that clonal evolution is not the main driver of clinical progression. Our analysis of the immune kinetics found an increasingly dysfunctional $C D 8^{+} T$ cell compartment in progressing patients that was not observed in those patients that remained asymptomatic. Specifically, terminally exhausted effector $C D 8^{+} T$ cells (T-bet ${ }^{\text {dim/- }}$ Eomes ${ }^{\text {hi } P D} 1^{\text {hi }}$ ) accumulated, while the the co-expression of inhibitory receptors (PD1, CD244 and CD160) increased, along with an altered gene expression profile in T cells only in those patients that progressed. In addition, malignant cells from patients at clinical progression showed enhanced capacity to induce exhaustion-related markers in $\mathrm{CD} 8^{+} \mathrm{T}$ cells ex vivo mainly through a mechanism dependent on soluble factors including IL-10.
\end{abstract}

Conclusions: Altogether, we demonstrate that the interaction with the immune microenvironment plays a key role in clinical progression in CLL, thereby providing a rationale for the use of early immunotherapeutic intervention.

Keywords: CLL, Immune evasion, Clinical progression, T cell exhaustion

\footnotetext{
*Correspondence: fbosch@vhio.net

${ }^{\dagger}$ Marta Crespo and Francesc Bosch contributed equally to this work.

2Department de Medicina, Universitat Autònoma de Barcelona, 08193 Bellaterra, Spain

${ }^{3}$ Servei d'Hematologia, Vall d'Hebron Hospital Universitari, Experimental Hematology, Vall d'Hebron Institute of Oncology (VHIO), Vall d'Hebron Barcelona Hospital Campus, Passeig Vall d'Hebron 119-129, 08035 Barcelona, Spain

Full list of author information is available at the end of the article
}

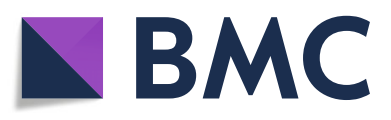

(- The Author(s). 2021 Open Access This article is licensed under a Creative Commons Attribution 4.0 International License, which permits use, sharing, adaptation, distribution and reproduction in any medium or format, as long as you give appropriate credit to the original author(s) and the source, provide a link to the Creative Commons licence, and indicate if changes were made. The images or other third party material in this article are included in the article's Creative Commons licence, unless indicated otherwise in a credit line to the material. If material is not included in the article's Creative Commons licence and your intended use is not permitted by statutory regulation or exceeds the permitted use, you will need to obtain permission directly from the copyright holder. To view a copy of this licence, visit http://creativecommons.org/licenses/by/4.0/. The Creative Commons Public Domain Dedication waiver (http://creativecommons.org/publicdomain/zero/1.0/) applies to the data made available in this article, unless otherwise stated in a credit line to the data. 


\section{Background}

Identification of patients that are at high risk of progression to advanced clinical stages needing treatment in chronic lymphocytic leukemia (CLL) is expedited by the use of different prognostic parameters including the mutational status of the IGHV genes or its surrogates like ZAP-70 expression [1, 2], chromosomal aberrations and gene mutations (i.e., TP53 or NOTCH1), [3, 4] or prognostic scores like the CLL-IPI [5]. Despite the great advances in the understanding of the biology of this disease over the last decade, the underlying mechanisms that drive clinical progression from early stages have not been fully deciphered yet.. Longitudinal genetic studies performed at the time of diagnosis and at progression before treatment show non-recurrent and limited changes in around half of the patients [6-15]. In agreement, changes in the gene expression profile of leukemic cells are also infrequent at progression [16]. These findings indicate that CLL progression from early stages is not mainly driven by genetic evolution, which highlights the potential role of the leukemic microenvironment in the evolution of the disease.

Besides the generalized immune dysfunction observed in patients diagnosed with CLL [17], circulating $\mathrm{T}$ cells from these patients exhibit an increased proportion of dysfunctional and exhausted antigen-experienced cells characterized by high expression of inhibitory receptors, impaired proliferation and cytotoxic activity as well as a defective immune synapse with leukemic cells, [18-22] all indicating defective anti-tumor $\mathrm{T}$ cell responses. Moreover, the immunosuppressing microenvironment prevalent in CLL is also boosted by the expansion of myeloid-derived suppressor cells (MDSCs) [23] and the production of IL-10 by CLL cells [24], among other factors.

These observations led us to hypothesize that a disease-induced $\mathrm{T}$ cell exhaustion accumulating from diagnosis could translate into an escape from immune surveillance driving CLL from early asymptomatic stages to clinical progression. To identify mechanisms of clinical progression we studied the specific changes that occur in patients that progress compared to those that remain asymptomatic along time. In detail, we performed genetic and immunological longitudinal analysis using paired primary samples from untreated CLL patients that experienced clinical progression (sampling at diagnosis and at progression) and from patients with stable disease (sampling at diagnosis and at long-term asymptomatic follow-up). Our results show that CLL cells exhibit limited and non-recurrent genetic changes at progression while $\mathrm{CD}^{+} \mathrm{T}$ cells display increased exhaustion features, potentially induced by IL-10 secreted by malignant $\mathrm{B}$ cells, and a differential transcriptome at progression. In contrast, patients without evidence of progression did not experience significant changes over time in their $\mathrm{CD}^{+} \mathrm{T}$ cell exhaustion status and the capacity of malignant cells to induce $\mathrm{T}$ cell exhaustion and to secrete IL-10 was lower compared to malignant cells from progressing patients and maintained over time.. These results could contribute to lay the foundations for the clinical testing of early therapeutic interventions on the immune system to prevent or delay progression of the disease.

\section{Methods}

\section{Primary samples}

Thirty eight patients diagnosed with CLL were enrolled in the study. Peripheral blood mononuclear cells (PBMCs) were isolated by Ficoll density gradient and cryopreserved. Plasma was obtained from EDTA blood and stored at $-80^{\circ} \mathrm{C}$. Samples were collected at two time points: diagnosis and progression before treatment or long-term asymptomatic follow-up. For most of the experiments, only a subgroup of the patients is represented due to availability of samples. For co-culture assays, PBMCs from age-matched healthy donors were used (HD; $n=17 ; 64$ years old). A written informed consent was obtained from all individuals in accordance with the declaration of Helsinki and the study was approved by the local clinical research ethics committee.

\section{Whole-exome sequencing (WES) and data processing}

Libraries for WES were sequenced on HiSeq2500 (Illumina, San Diego, CA, USA) with a read length of $100 \mathrm{bp}$ paired-end. Raw data was processed using the Real Time Analysis software (RTA 1.18.66.3, Illumina) to generate FASTQ sequence files, which were processed using the bioinformatics software HD Genome One (DREAMgenics, Oviedo, Spain).

The detection of copy number variations (CNVs) was performed by a modified version of the exome $2 \mathrm{cnv}$ algorithm [25]. For tumor samples, the algorithm employed a pool of all control samples as background. The cancer cell fraction (CCF) and the 95\% confidence interval (CI) were computed using the $R$ package Palimpsest [26]. See Supplementary Methods for detailed information.

\section{RNA sequencing (RNA-Seq) and data processing}

Libraries for RNA-Seq were sequenced on HiSeq2500 (Illumina) with a read length of $100 \mathrm{bp}$ paired-end. Reads were mapped against the human reference genome (GENCODE release 28) and genes were quantified as detailed in Supplementary Methods.

\section{Flow cytometry analysis}

Cryopreserved PBMCs were thawed and stained with monoclonal antibodies (mAbs, Supplementary Table S1) as detailed in Supplementary Methods. 
For the assessment of intracellular IL-10 produced by CLL cells, PBMCs were co-cultured for $48 \mathrm{~h}$ with UE6E7T-2 cells, CD40L (Peprotech, Rocky Hill, NJ, USA) and TLR9L (CpG ODN2006, Invivogen, San Diego, CA, USA) as we previously described [27] and then cells were stimulated with Leukocyte Activation Cocktail (BD Biosciences, Franklin Lakes, NJ, USA) for $5 \mathrm{~h}$ prior to staining.

Cells were acquired by a Navios ${ }^{\text {Tw }}$ cytometer (Beckman Coulter, Brea, CA, USA). Data were analyzed using the FlowJo v10 software (TreeStar, Ashland, OR, USA) and the Cytobank platform (Santa Clara, CA, USA).

\section{Determination of IL-10 in plasma}

Concentrations of plasmatic IL-10 were measured using the Simple Plex ${ }^{\mathrm{Tm}}$ Assay for the detection of human IL-10 (R\&D Systems, Minneapolis, MN, USA) on Ella ${ }^{\text {Tw }}$ Automated ELISA Platform following the manufacturer's instructions.

\section{$B$ and T lymphocytes co-cultures}

After negative selection, B-CLL cells or B cells from HD were co-cultured with $\mathrm{T}$ cells from CLL or HD at 1:2 and 1:10 T to B cell ratios as detailed in Supplementary Methods.

\section{Statistical analysis}

Comparisons were performed using the Wilcoxon matched-pairs rank test or the Mann-Whitney $U$ test in unpaired samples. Differences were considered statistically significant if $P<0.05$. All the statistical analyses were carried out and graphed using the GraphPad Prism version 6.0 software.

\section{Results}

CLL cells show limited and non-recurrent genetic changes at clinical progression

In a series of 25 patients (median age: 63 years, range 40-82 years) that experienced clinical progression (median time to progression (TTP): 29 months, range 596 months), we collected serial paired samples at diagnosis and at the time of progression before treatment. Definition of progression and requirement for treatment were established following the international workshop on CLL (IWCLL) criteria [28]. As a control group, we collected serial samples at diagnosis and at follow-up from 13 patients that had stable disease (median age: 66 years, range $47-81$ years; median time to second sampling: 39 months, range $30-77$ months). For this group, the median follow-up was 77 months (range 41-101 months) and only one patient (CLL46) progressed (19 months after second sampling). Clinical characteristics are summarized in Table 1 and detailed in Supplementary Table S2.

For the purpose of analyzing potential genetic evolution related to clinical progression, we performed longitudinal WES in paired samples from 12 patients at diagnosis and progression. With a mean read depth of $110 \mathrm{X}$, the limit of detection was set at a minimum coverage of 20 reads and a minimum of 0.1 variant allele frequency (VAF). In accordance with previous WES studies in CLL, mutation rate at both time points was low and consisted of a mean \pm SEM (standard error of the mean) of $12.2 \pm 3.3$ (range 6-17) somatic single nucleotide variants (SNVs) and insertions and deletions (indels) per exome. (Supplementary Table S3). We then screened for clonal shifts from diagnosis to progression by calculating significant changes in the CCF of the alterations detected in each patient [29] (see supplementary methods for detailed information about CCF calculation). A significant change was determined if the 95\% confidence intervals of the CCF in the diagnosis and progression sample did not overlap [29]. We found that $50 \%$ of patients showed significant changes at progression affecting the CCF of at least one alteration. However, the remaining $50 \%$ of patients exhibited clonal stability at clinical progression (Fig. 1a and b). At diagnosis, mutations in CLL driver genes [29,30] were found

Table 1 Clinical characteristics of progressing and non-progressing patients

\begin{tabular}{|c|c|c|c|c|}
\hline & \multicolumn{2}{|c|}{ Progressed } & \multicolumn{2}{|c|}{ Non-progressed } \\
\hline Gender & \multicolumn{2}{|l|}{$M(68 \%)$} & \multicolumn{2}{|l|}{ M (69\%) } \\
\hline BINET/RAI stage at diagnosis & \multicolumn{2}{|l|}{$\mathrm{A} 0(72 \%)$} & \multicolumn{2}{|l|}{ A0 (92\%) } \\
\hline \multirow[t]{2}{*}{ IGHV Status } & \multicolumn{2}{|l|}{ UM (56\%) } & \multicolumn{2}{|l|}{ UM (8\%) } \\
\hline & Median & Range & Median & Range \\
\hline Age at diagnosis & 63 & $40-82$ & 66 & $47-81$ \\
\hline TTP (months) & 29 & $5-96$ & - & - \\
\hline Follow-up without progression (months) & - & - & 77 & $41-101$ \\
\hline Time to second sampling (months) & 29 & $5-96$ & 39 & $30-77$ \\
\hline Lymphocytes $\cdot 10^{9} / \mathrm{L}$ at diagnosis & 12.20 & 3.3-65.8 & 10.40 & $3.8-31.2$ \\
\hline Lymphocytes $\cdot 10^{9} / \mathrm{L}$ at second sampling & 73.05 & $2.3-287.1$ & 22.40 & $5.2-85.3$ \\
\hline
\end{tabular}




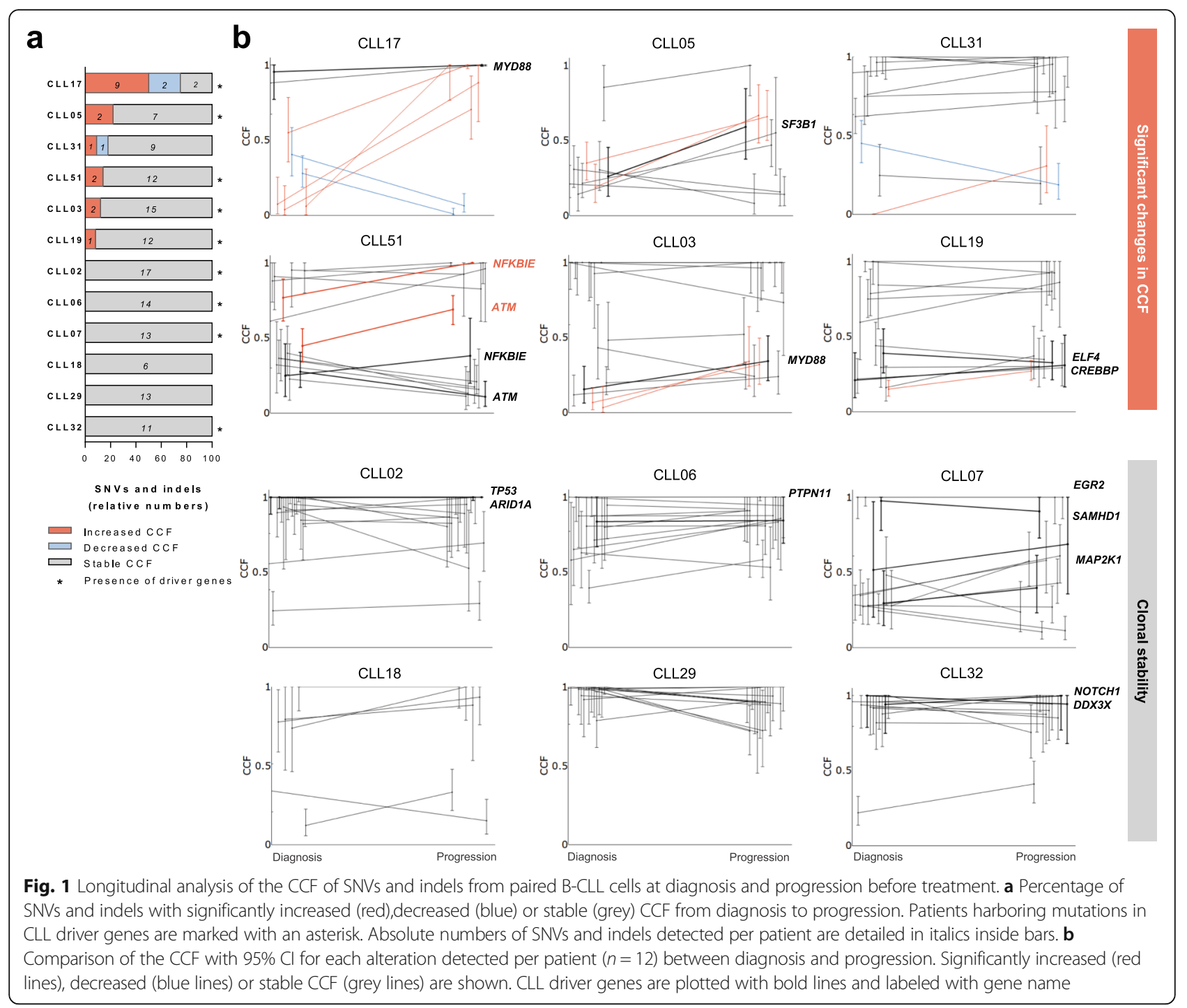

in 9 out of $12(75 \%)$ patients (mean \pm SEM of $1.4 \pm 1.2$ drivers per patient) (Fig. 1a). Among these, only one patient (CLL51) showed increased size of drivers CCF at progression: two variants in NFKBIE and ATM genes rised at progression (Fig. 1b, in bold red). Also in this patient, two additional variants from the same genes had fixed CCF between time points (Fig. 1b, in bold black). Furthermore, one patient (CLL31) among those without alterations in driver genes acquired a mutation at progression affecting the gene TENM1 $(C C F=0.31)$ (Fig. 1b), not previously associated with CLL.

We also analyzed the mutational status of 9 CLL driver genes (TP53, BIRC3, ATM, NOTCH1, SF3B1, XPO1, MYD88, FBXW7 and POT1) by targeted next generation sequencing in the same patients. With a mean read depth of 2000X, the limit of detection was set at a minimum coverage of 100 reads and a minimum of 0.05 VAF. Despite high depth sequencing, no additional changes over time affecting these drivers were observed (Supplementary Table S4).

Regarding changes in CNVs by WES, at diagnosis, CNVs were detected in 10 out of 12 (83\%) patients with a mean \pm SEM of $4.0 \pm 4.1$ (range 1-12) CNVs per patient (Supplementary Table S5 and Supplementary Fig. S1). Seven out of 12 (58\%) patients had recurrent CNVs associated with CLL, including del(13q), tri(12), $\operatorname{del}(11 q)$ and $\operatorname{del}(17 p)(3)$, but all remained stable over time. Nonetheless, we did observe acquisition of del(8p) and $\operatorname{del}(15 p)$ with a CCF of 72 and $44 \%$, respectively, at progression in the same patient that showed increased CCF in driver genes (CLL51).

For patients without clinical progression, we analyzed the panel of CLL driver genes in paired B-CLL cells at diagnosis and asymptomatic follow-up ( $n=9$ patients). We identified mutations at diagnosis in 4 out of $9(44 \%)$ non-progressing patients. One of them (CLL23) displayed 
increased VAF in one $A T M$ variant, and another one (CLL47) showed reduced VAF in one mutation affecting FBXW7 at second sampling (Supplementary Table S4).

Altogether, these results indicate that adquisition or expansion of genetic alterations is not linked to naturally occurring clinical progression, as previously reported by others $[6-12,14,15]$.

\section{Effector memory $\mathrm{CD}^{+} \mathrm{T}$ cells co-expressing inhibitory receptors accumulate at CLL progression while they remain steady over time in patients with stable disease} Prior studies in patients diagnosed with CLL have shown an increase in defective circulating $\mathrm{CD}^{+} \mathrm{T}$ cells displaying a terminally differentiated phenotype compared to aged-matched healthy donors [18-21, $31,32]$. However, how these $\mathrm{CD}^{+} \mathrm{T}$ cells potentially evolve from diagnosis to clinical progression using longitudinal samples has not yet been studied. To investigate this, we analyzed the immunophenotype of $\mathrm{T}$ cells in paired PBMC samples from our two cohorts: 19 patients were analyzed at time of diagnosis and progression before treatment and 10 patients were analyzed at time of diagnosis and a second time point during follow-up without progression (from here referred to as "non-progression"). Firstly, the CD4/CD8 ratio at second sampling was significantly decreased over time only in patients that progressed, in whom effector memory $\mathrm{CD}^{+} \mathrm{T}$ cells $\left(\mathrm{T}_{\mathrm{EM}}\right.$ : $\mathrm{CCR}^{-} \mathrm{CD}^{-} 5 \mathrm{RA}^{-}$) were the sole expanded T cell subset at progression, whereas no significant changes in $\mathrm{CD}^{+} \mathrm{T}$ cells maturation subsets were observed in non-progressors (Supplementary Fig. S2a and b).

PD1 is expressed in chronically stimulated $\mathrm{CD}^{+} \mathrm{T}$ cells and has a relevant role in $\mathrm{T}$ cell exhaustion $[33,34]$. It also has been described as preferentially expressed in effector memory $\mathrm{CD} 8^{+} \mathrm{T}$ cells, which are increased in CLL compared to healthy donors $[18,21]$. Here, we observed an accumulation of PD1expressing $\mathrm{CD}^{+}{ }^{+} \mathrm{T}$ cells (Supplementary Fig. S2c) and an enrichment in $\mathrm{PD} 1^{+} \mathrm{T}_{\mathrm{EM}}$ and $\mathrm{PD} 1^{+} \mathrm{T}_{\mathrm{EMRA}} \mathrm{CD} 8^{+}$subsets. This increase in exhausted $\mathrm{CD} 8^{+} \mathrm{T}$ cells was not observed at non-progression (Fig. 2a to c). To further investigate whether other features of $\mathrm{T}$ cell exhaustion and impaired effector function in $\mathrm{CD}^{+} \mathrm{T}$ cells were also enhanced at CLL progression, we measured the co-expression of PD1 with other inhibitory receptors, namely CD244 and CD160 [33, 35]. In line with our previous findings, we observed that $\mathrm{CD}^{+} \mathrm{T}$ cells co-expressing PD1 with CD244 or CD160 significantly rose only at progression, although the fold-change increase in $\mathrm{CD}^{+} \mathrm{T}$ cells expressing $\mathrm{PD} 1^{+} \mathrm{CD} 160^{+}$was not significantly higher than the one observed in non-progressing patients (Supplementary Fig. S2d to f). In addition, the expanded $\mathrm{T}_{\mathrm{EM}} \mathrm{CD} 8^{+}$subset in progressing patients gained features of severe exhaustion at the time of progression as denoted by higher coexpression of PD1 with CD244 or CD160 (Fig. 2d and e). Altogether, we observed a longitudinal increase from diagnosis to progression in antigen-experienced effector memory $\mathrm{CD}^{+} \mathrm{T}$ cell subsets together with an increased co-expression of inhibitory receptors. On the contrary, no significant changes were observed over time in patients that did not progress.

\section{Terminally exhausted $\mathrm{CD}^{+}{ }^{+} \mathrm{T}$ cells ( $\mathrm{T}$ - bet ${ }^{\text {dim/- }}{ }^{-}$-omes ${ }^{\text {hi }}$ PD $1{ }^{\text {hi }}$ ) accumulate at CLL progression}

T-bet and Eomesodermin (Eomes) are two T-box transcription factors that regulate the differentiation process of $\mathrm{CD}^{+} \mathrm{T}$ cells after antigen encounter and cooperate in the maintenance of long-term immunity [36]. Several studies have pointed out that they both have roles in $\mathrm{CD}^{+} \mathrm{T}$ cell exhaustion. T-bet represses PD1 expression and other inhibitory receptors [37] while Eomes, in contrast, is related to high expression of multiple inhibitory receptors, including PD1 [38, 39]. Accordingly, differential expression of both transcription factors combined with moderate or high PD1 levels defines two distinctly exhausted $\mathrm{CD}^{+} \mathrm{T}$ cell subsets: the progenitor (T-bet ${ }^{\text {hi }}$ Eomes ${ }^{\mathrm{dim} /-} \mathrm{PD} 1^{\mathrm{mid}}$ ) and the terminal progeny (T-bet ${ }^{\mathrm{dim} /-}$ Eomes $^{\mathrm{hi}} \mathrm{PD} 1^{\mathrm{hi}}$ ) [38] (Supplementary Fig. S3). Moreover, higher expression of Eomes in $\mathrm{CD}^{+} \mathrm{T}$ cells has been observed in patients diagnosed with CLL compared to HD and its function is essential for proper $\mathrm{T}$ cell expansion in CLL mouse models [40]. Since we observed that $\mathrm{CD}^{+} \mathrm{T}$ cells from CLL patients gained features of a more severe exhaustion degree at progression, we hypothesized that the terminal progeny would also be increased at progression. Indeed, we found that the $\mathrm{CD}^{+}$progenitor subset remained stable over time in both progressors and nonprogressors (Fig. 3a and c), while the terminally exhausted $\mathrm{CD}^{+}$subpopulation (T-bet ${ }^{\mathrm{dim} /-}$ Eomes $^{\mathrm{hi}} \mathrm{PD} 1^{\mathrm{hi}}$ ) was significantly increased only in progressing patients (Fig. $3 \mathrm{~b}$ and c). These findings confirm that $\mathrm{CD}^{+} \mathrm{T}$ cells at progression exhibit a severe terminal exhaustion condition likely impairing their ability to control the growth of malignant cells.

\section{T cells acquire a distinct transcriptional profile at CLL progression}

In order to broadly characterize the alterations that occur over time in $\mathrm{T}$ cells from patients diagnosed with CLL cells related to clinical progression, we performed paired RNA-Seq analysis on isolated $\mathrm{T}$ cells (mean purity of 92\%): 13 patients were analyzed at time of diagnosis and progression and 6 patients were analyzed at diagnosis and at follow-up (non-progression). After selecting uniquely mapped reads, the unsupervised hierarchical clustering analysis of paired 


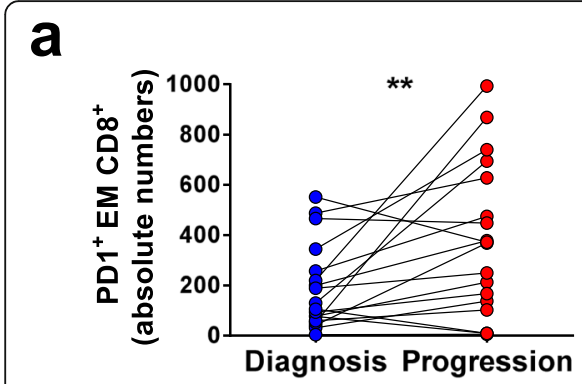

b
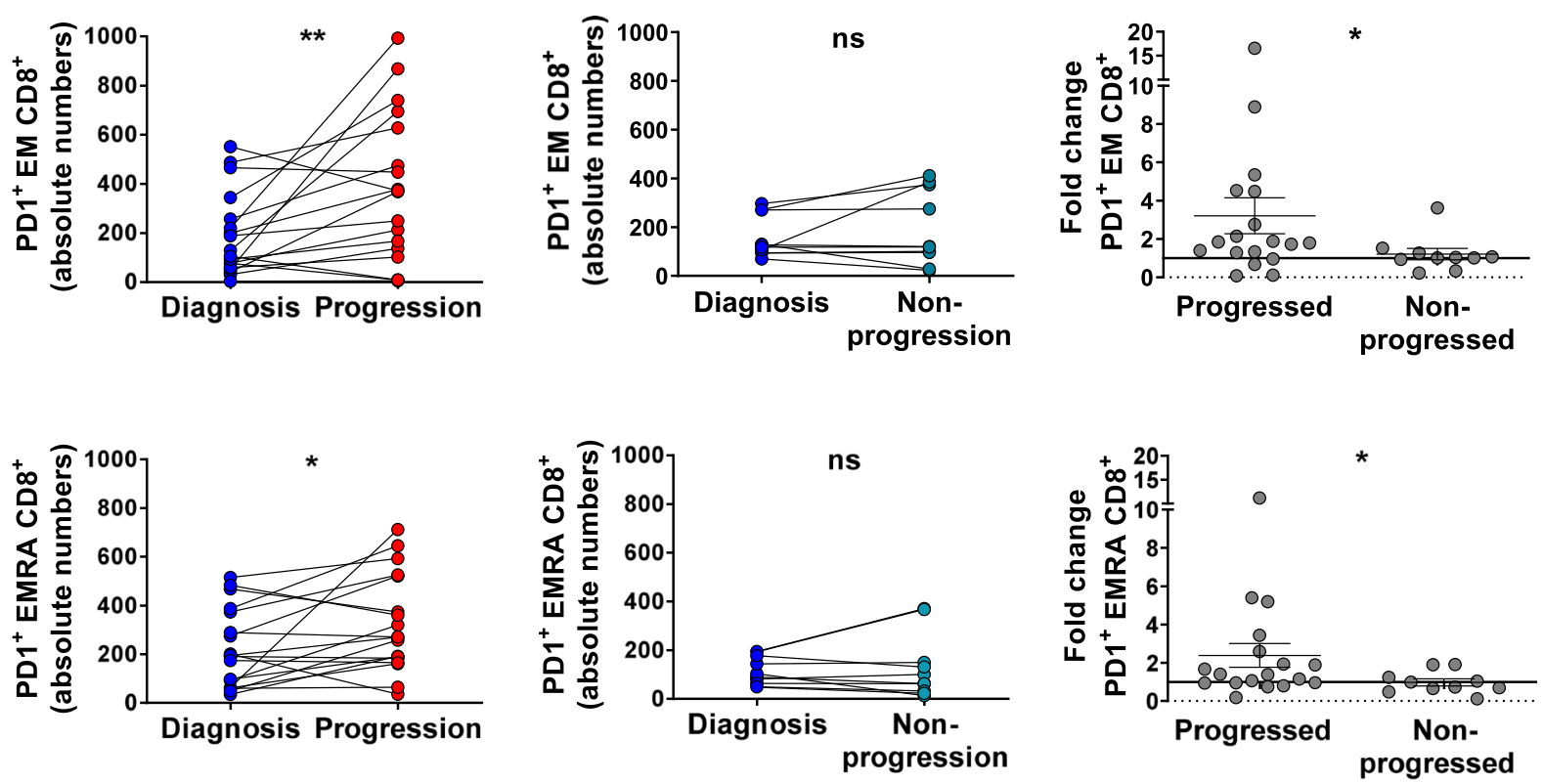

C
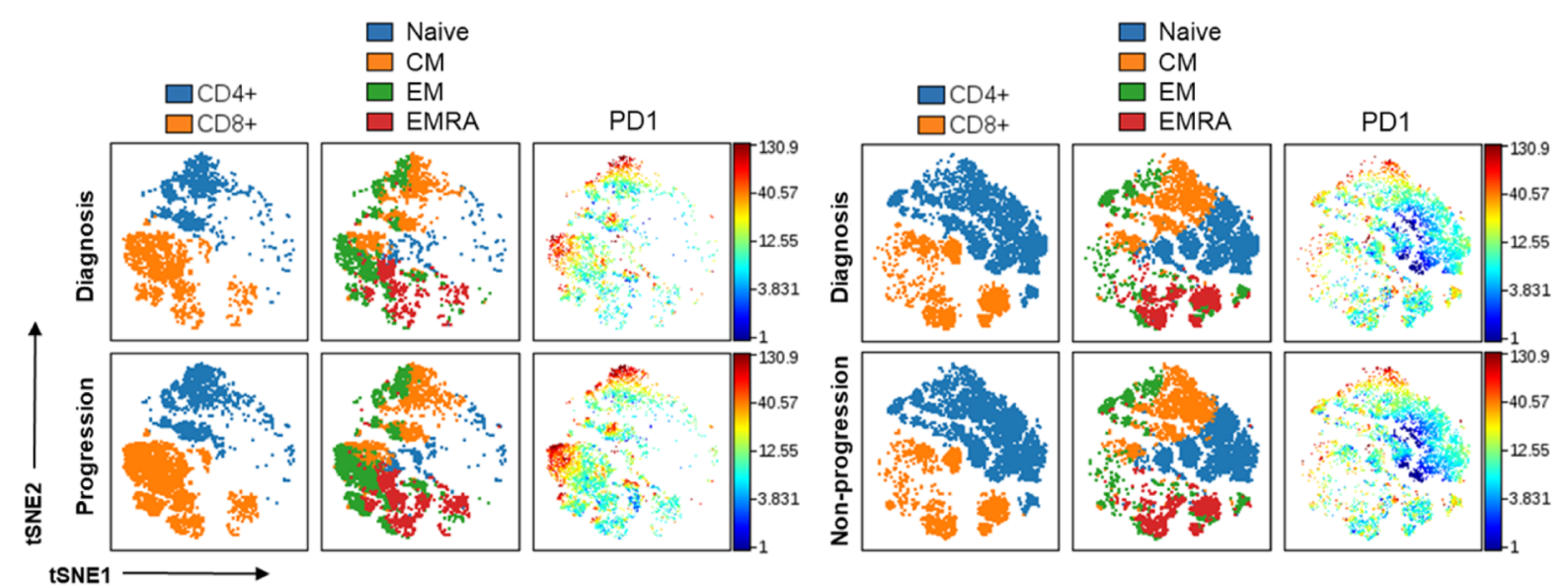

\section{d}
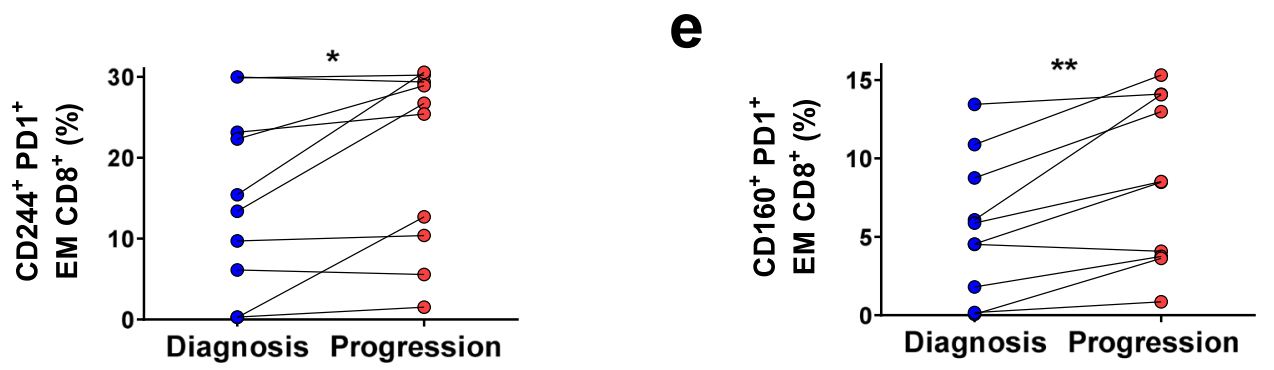

Fig. $2 \mathrm{PD}^{+}$effector memory $\mathrm{CD} 8^{+} \mathrm{T}$ cells subsets and co-expression of inhibitory receptors in progressing and non-progressing CLL patients. a Absolute numbers of PD1 ${ }^{+} \mathrm{EM}$ and $\mathbf{b} \mathrm{PD} 1^{+}$EMRA CD8 ${ }^{+} \mathrm{T}$ cells in progressing (left, $n=18$ ) and non-progressing patients (middle, $\left.n=10\right)$ at diagnosis and progression or non-progression. Fold change between time points of $\mathrm{PD} 1^{+} \mathrm{EM}$ and PD1 ${ }^{+} \mathrm{EMRA} \mathrm{CD} 8^{+}$cells in progressing and non-progressing patients (right). c Representative viSNE plots of T cell differentiation subsets (naïve: CCR7 ${ }^{+} C D 45 R A^{+}$; central memory, CM: CCR7 ${ }^{+} C D 45 R A^{-}$; effector $^{2}$

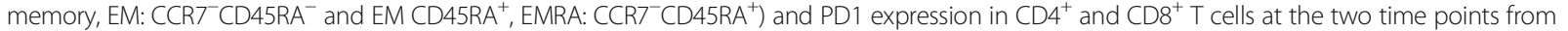
one representative patient from each group. $\mathbf{d}$ Percentages of EM CD8 ${ }^{+}$cells co-expressing CD244 and PD1 ( $\left.n=12\right)$ and e CD160 and PD1 ( $\left.n=10\right)$. Graphs show mean \pm SEM or paired values. $\left({ }^{*} P<0.05 ;{ }^{* *} P<0.01\right.$; ${ }^{* *} P<0.001$; Wilcoxon matched paired test or Mann-Whitney test) 


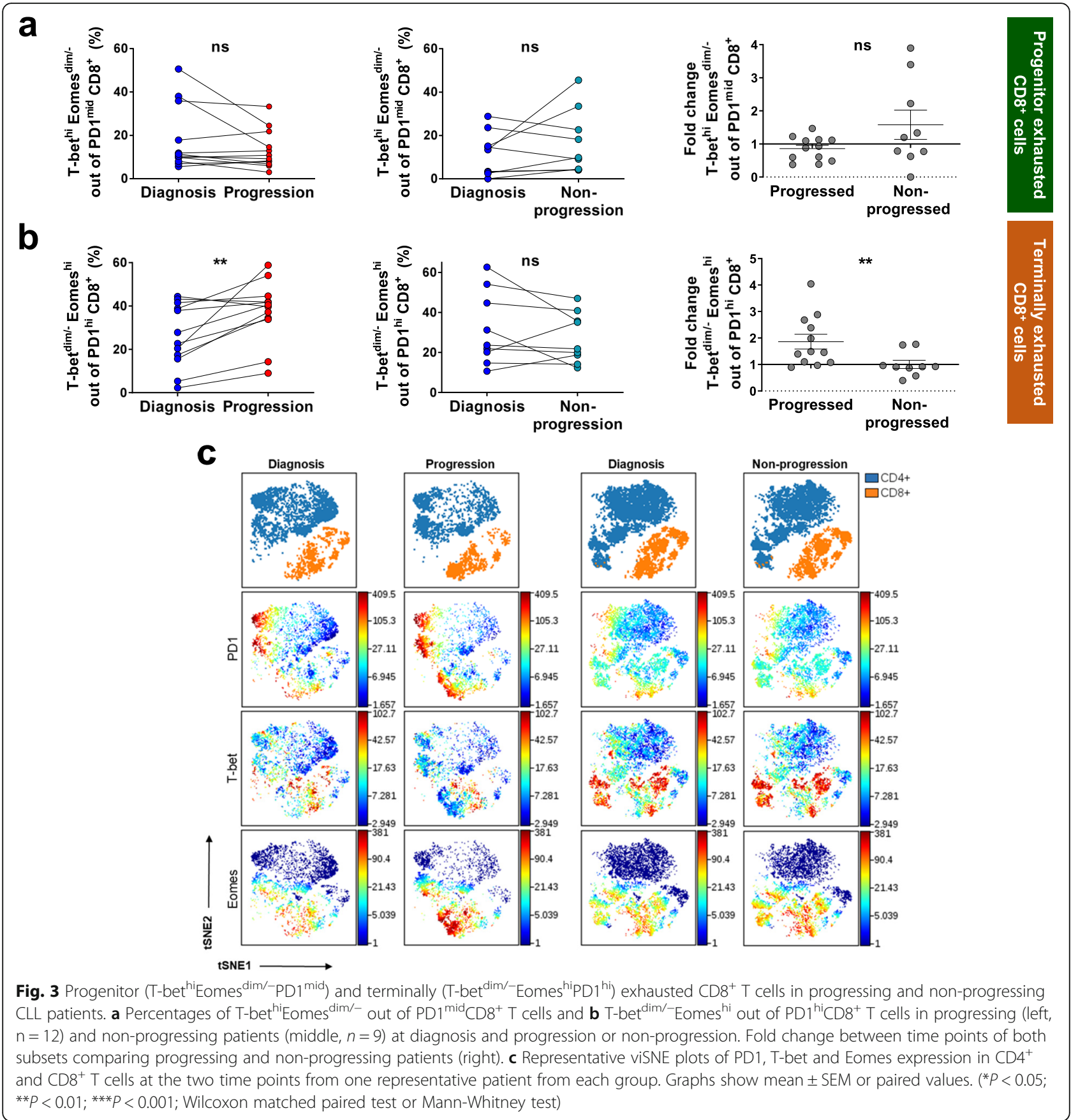

samples from progressing patients defined two main clusters: one corresponding exclusively to $\mathrm{T}$ cells at progression and another cluster including $\mathrm{T}$ cells at diagnosis plus two samples at progression, highlighting that the transcriptional profile of $\mathrm{T}$ cells at progression was clearly distinct from that of $\mathrm{T}$ cells at diagnosis (Fig. 4). A total of 80 genes (including protein coding and lncRNA transcripts) were significantly up or downregulated in $\mathrm{T}$ cells from diagnosis to progression, while in contrast only 3 genes were differentially expressed in $\mathrm{T}$ cells from non-progressed patients at the time of follow-up after supervised analysis (all genes padj $<0.05$ are detailed in Supplementary Table S6). Moreover, those 3 differentially expressed genes found in non-progressing patients were also found at progression. Briefly, the transcriptional profile of $\mathrm{T}$ cells at progression suggests lower mobility and differentiation capacity as well as an impairment in mitochondrial oxidative phosphorylation (Supplementary Table S7), essential processes for the maintenance of $\mathrm{T}$ 


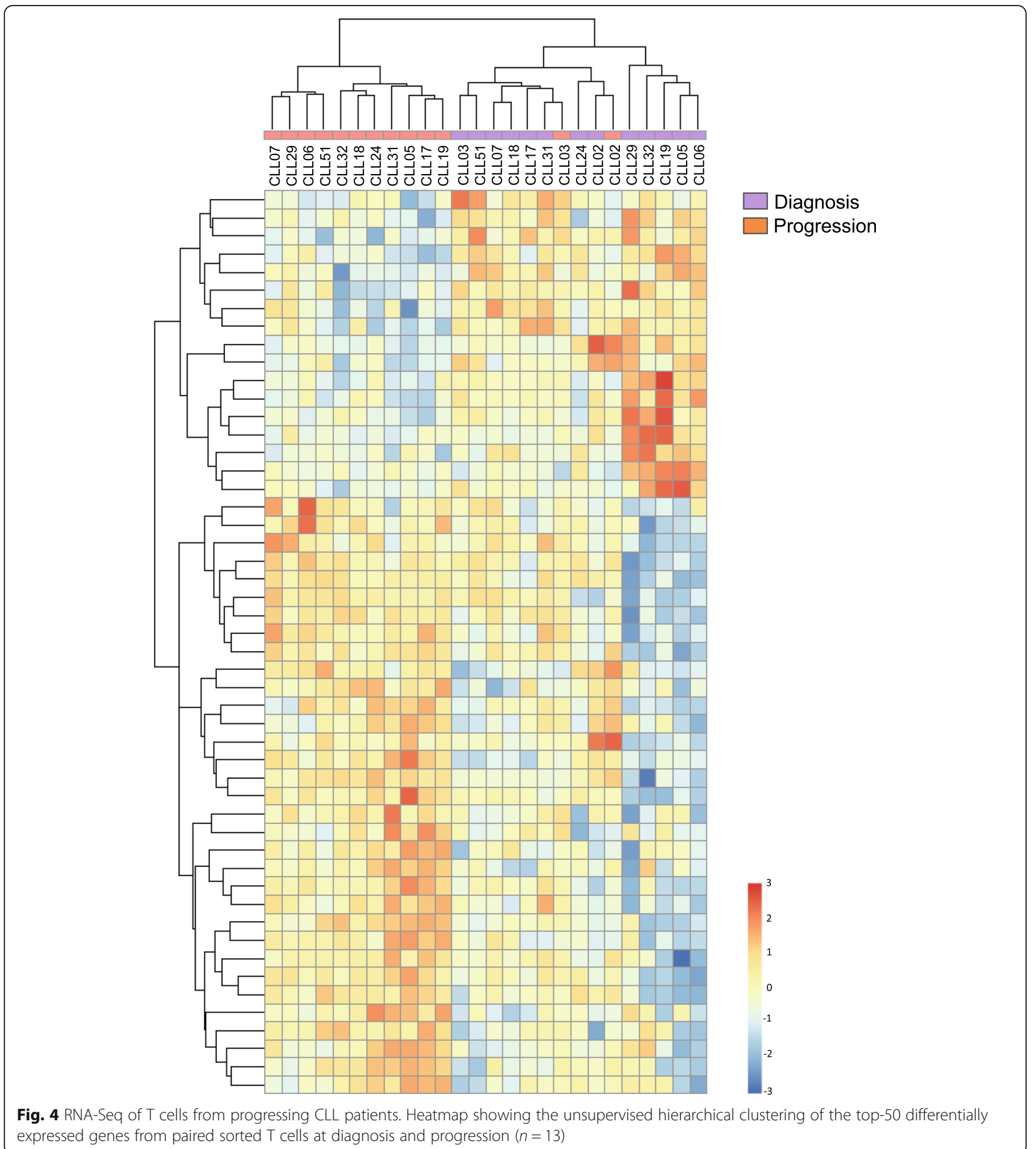

cell effector functions [41]. Additionally, genes related to fatty acids and amino acids catabolism and glucose transporters were upregulated, while lower expression of genes related to the synthesis of cellular components and RNA processing mechanisms were identified at progression, suggesting a potentially dysregulated $\mathrm{T}$ cell metabolism. $\mathrm{T}$ cells at progression also showed upregulation of genes associated with immune response and exhaustion [42-44]. Collectively, these results point towards an impaired cytoskeleton formation, mitochondrial metabolism and immune dysregulation, consistent with the exhausted and dysfunctional status of $\mathrm{T}$ cells that is aggravated at CLL progression. 
CLL cells from patients at clinical progression have enhanced capacity to induce PD1 expression in $\mathrm{CD}^{+} \mathrm{T}$ cells via soluble factors including IL-10

The observed increased exhaustion at progression compared to patients that had not progressed could be mainly caused by a potentially increased interaction with malignant cells due to higher tumoral load; alternatively, malignant cells at progression could be intrinsically more capable of inducing exhaustion in T cells. In order to gain insight into the functional mechanisms that could trigger said increased exhaustion of $\mathrm{CD}^{+} \mathrm{T}$ cells, we compared the effect on $\mathrm{T}$ cells of malignant B-CLL cells obtained from patients at clinical progression vs. malignant cells from patients at follow-up of stable disease (non-progression). To do that we firstly co-cultured $\mathrm{T}$ cells from patients with CLL (T-CLL) with increasing concentrations of either healthy B cells (B-HD) or autologous B-CLL cells obtained from patients at progression or from patients at follow-up (non-progression). After 7 days of co-culture, we found that PD1 expression was increased in $\mathrm{CD}^{+} \mathrm{T}$ cells in presence of progressed $\mathrm{B}$-CLL cells at any leukemic cell to $\mathrm{T}$ cell ratio, while BHD cells did not induce changes in PD1 expression (Fig. 5a). Moreover, B-CLL cells from patients that did not progress were only able to induce PD1 expression in autologous $\mathrm{CD}^{+} \mathrm{T}$ cells at the highest $\mathrm{B}$ to $\mathrm{T}$ cell ratio tested, suggesting that there are intrinsic characteristics in malignant B cells from patients that are in need of treatment that can contribute to the observed $\mathrm{T}$ cell exhaustion. The same results were obtained when looking at PD1 and CD244 co-expression (supplementary Fig. S4a). Therefore, and in order to further compare the capacity to induce exhaustion of malignant B cells from patients at progression versus malignant cells from nonprogressing patients, we co-cultured $\mathrm{T}$ cells from healthy donors (T-HD) with both types of malignant cells. In this setting, only progressed B-CLL cells were capable of inducing PD1 expression in $\mathrm{CD} 8^{+} \mathrm{T}$ cells whereas nonprogressed B-CLL cells were not (Fig. 5c), while they showed no differences in the induction of PD1 and CD244 co-expression. Thus, although we cannot completely rule out that the observed enhanced exhaustion at progression is merely caused by increased tumoral load, these results indicate that malignant cells at progression are intrinsically more capable of inducing PD-1 expression in both autologous or HD-derived T cells.

To investigate whether this $\mathrm{T}$ cell state induced by CLL cells occurs through a cell-to-cell mediated mechanism or, otherwise, is mediated by soluble factors, TCLL and B-CLL co-cultures were performed with transwells. We observed that the induction of PD1 and $\mathrm{CD} 244$ in $\mathrm{CD}^{+} \mathrm{T}$ cells was equivalent when there was no contact between autologous $\mathrm{T}$ cells and leukemic cells (Fig. 5d and Supplementary Fig. S4c, suggesting that secretion of soluble factors lead to upregulation of exhaustion markers. In this regard, CLL cells are known to exhibit features of regulatory B cells, such as IL-10 production, [24] which has been found to have immunosuppressive function in CLL $[45,46]$, be related to shorter overall survival [47] and to correlate with the expression of PD1 in tumor infiltrating lymphocytes in solid tumors [48]. Based on this, we initially measured the levels of IL-10 in paired plasma samples from CLL patients and found that plasmatic IL-10 significantly increased at progression while remained stable over time in non-progressing patients (Fig. 5e). Next, to investigate whether malignant cells acquire an increased capacity to produce IL-10 at progression and, therefore, higher plasmatic levels are not simply reflecting the higher tumoral load at progression, we assessed the production of IL-10 by CLL cells in vitro after microenvironmental stimuli [27]. We detected an increased percentage of $\mathrm{IL}^{-10^{+}}$ CLL cells only in malignant cells obtained at progression (Fig. $5 f$ and Supplementary Fig. S4d), indicating that leukemic cells from patients at clinical progression have indeed increased potential to create an immunosuppressive microenvironment. Moreover, the induction of PD1 expression in vitro in $\mathrm{CD} 8^{+} \mathrm{T}$ cells was partially blocked after IL-10 neutralization (Fig. 5g). Finally, we analyzed the potential accumulation of MDSCs as an additional source of plasmatic IL-10, and we observed [49] an accumulation of these immunosupresive cells over time in all CLL patients regardless of their clinical evolution, although the degree of increment was higher in progressing patients (Supplementary Fig. S4e). These observations suggest that at the time of progression not only there is an increased load of leukemic cells, but these also have a higher IL-10 capacity production, which can contribute to the increased induction of $\mathrm{CD}^{+} \mathrm{T}$ cell exhaustion.

\section{Discussion}

The biological processes that lead to clinical progression from early asymptomatic stages in patients diagnosed with CLL are not well understood and, consequently, the pathogenesis behind the natural history of this disease remains unclear. In this regard, longitudinal studies from diagnosis to clinical progression are essential to elucidate these mechanisms. To the best of our knowledge, this is the first comprehensive longitudinal analysis of the genetic and immunological processes driving disease progression in CLL. The longitudinal molecular study herein presented showed limited and non-recurrent molecular changes in CLL cells at progression, indicating that genetic clonal evolution is not the main driver of clinical progression, like previously observed in other series [6-15]. Conversely, longitudinal studies focused on potential changes in the immune 


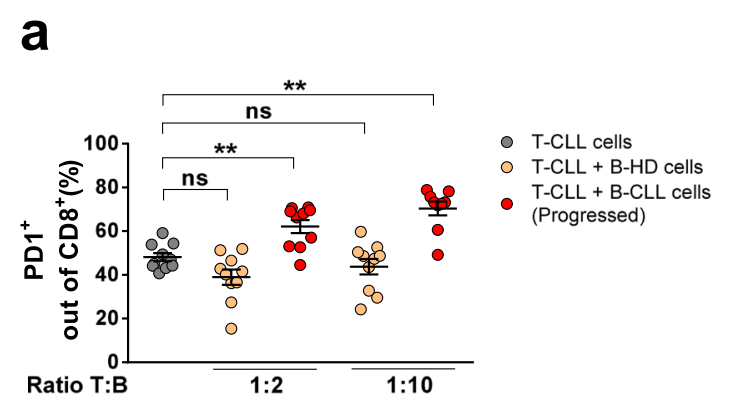

C

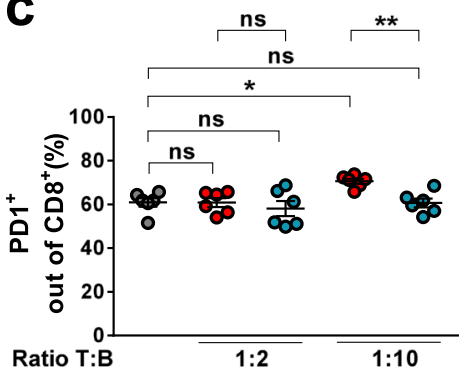

b
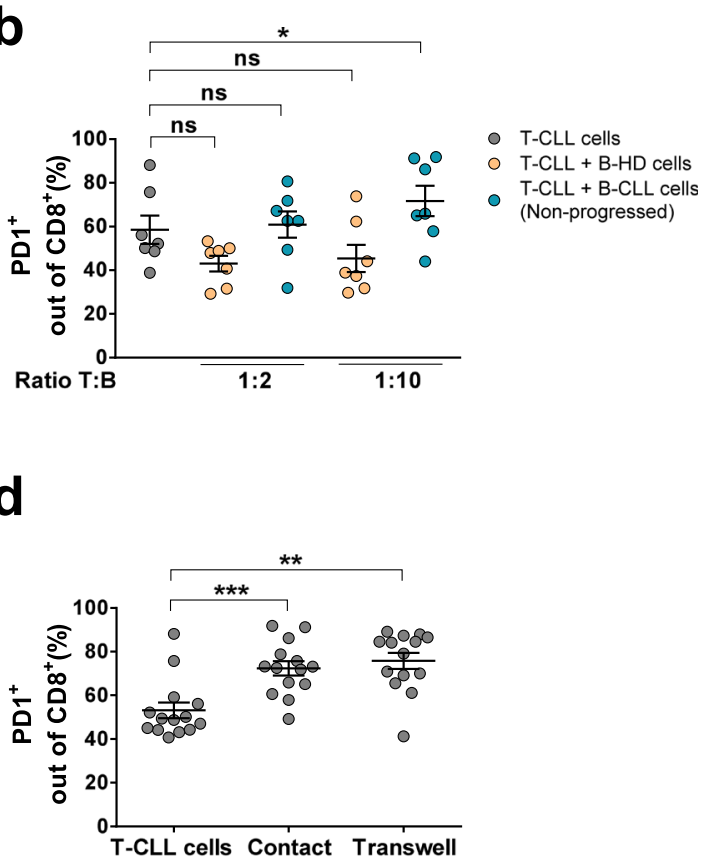

e

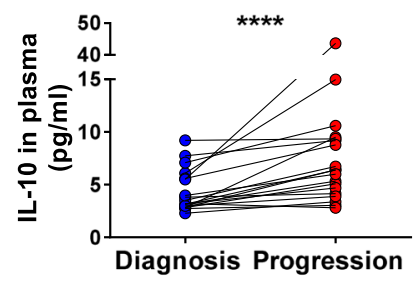

f

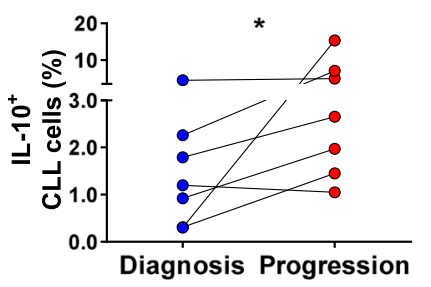

d
- T-HD cells

T-HD + B-CLL cells

(Progressed)

T-HD + B-CLL cells
(Non-progressed)
Ratio T:B$$
1: 10
$$
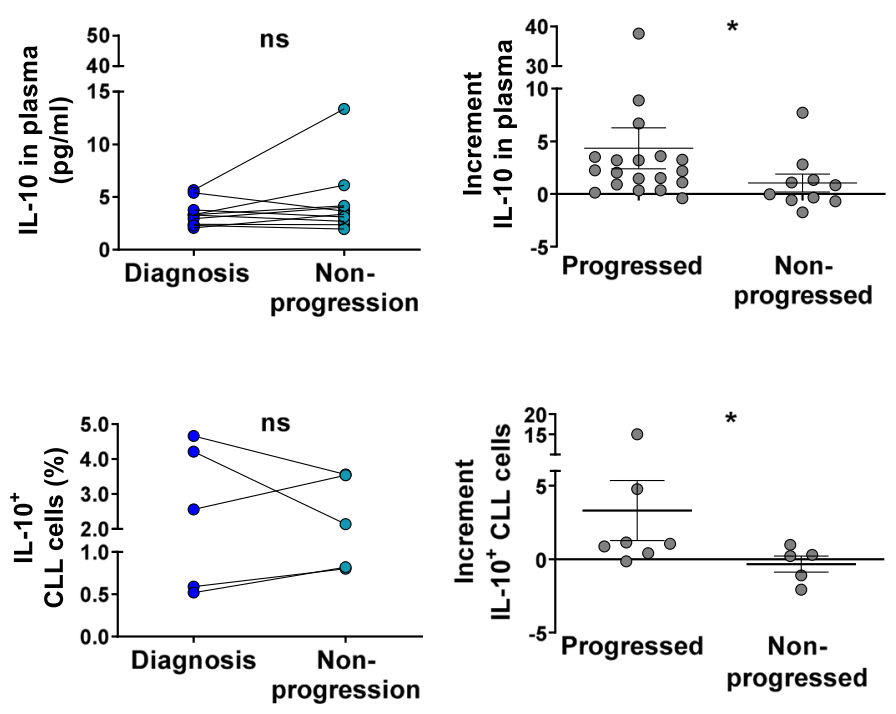

9

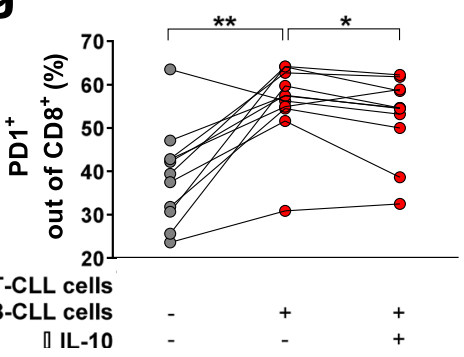

Fig. 5 (See legend on next page.) 
(See figure on previous page.)

Fig. 5 PD1 expression in CD8 ${ }^{+} T$ cells after co-culture with B-HD cells or B-CLL cells and contribution of soluble factors to PD1 expression. a Percentages of $\mathrm{PD}^{+}{ }^{+} \mathrm{CD}^{+} \mathrm{T}$ cells from progressing CLL patients after stimulation with anti-CD3 and anti-CD28 for 7 days (grey dots) and in presence of B-HD cells (yellow dots) or B-CLL cells at the time of progression (red dots) at the indicated T:B ratios $(n=10)$. $\mathbf{b}$ Percentages of $\mathrm{PD}^{+}{ }^{+} \mathrm{CD} 8^{+} \mathrm{T}$ cells from non-progressing CLL patients after stimulation with anti-CD3 and anti-CD28 for 7 days (grey dots) and in presence of BHD cells (yellow dots) or B-CLL cells at asymptomatic follow-up (blue dots) at the indicated T:B ratios $(n=7)$. c Percentages of PD $1^{+} \mathrm{CD} 8^{+} \mathrm{T}$ cells from age-matched healthy donors (T-HD) after stimulation with anti-CD3 and anti-CD28 for 7 days (grey dots) and in presence of B-CLL cells at progression (bold red dots) or B-CLL cells at asymptomatic follow-up (bold blue dots) at the indicated T:B ratios $(n=6)$. d Percentages of $\mathrm{PD} 1^{+} \mathrm{CD} 8^{+} \mathrm{T}$ cells from CLL patients after stimulation with anti-CD3 and anti-CD28 for 7 days and in contact with B-CLL cells or separated by transwell inserts at 1:10 T:B ratio $(n=14)$. e Concentration $(\mathrm{pg} / \mathrm{ml})$ of $\mathrm{IL}-10$ in plasma from progressing (left, $n=19)$ and non-progressing patients (middle, $\mathrm{n}=10$ ). Increment of IL-10 in plasma between time points comparing progressing and non-progressing patients (right). $\mathbf{f}$ Percentage of $\mathrm{IL}-10^{+} \mathrm{CLL}$ cells in progressing (left, $n=7$ ) and non-progressing patients (middle, $n=5$ ) at the two time points after co-culture of paired PBMCs with bone marrow stromal UE6E7T-2 cells, CD40L and TLR9L for $48 \mathrm{~h}$. Increment of IL-10 $\mathrm{CLL}$ cells between time points in progressing and nonprogressing patients (right). $\mathbf{g}$ Percentage of $\mathrm{PD} 1^{+} \mathrm{CD} 8^{+} \mathrm{T}$ cells from $\mathrm{CLL}$ after 7-day co-culture with progressing B-CLL cells at 1:10 T:B ratio, following the protocol previously described, and after adding anti-human IL-10 neutralizing antibody $(n=11)$. Graphs show mean \pm SEM or paired values $\left({ }^{*} P<0.05 ;{ }^{* *} P<0.01 ;{ }^{* *} P<0.001 ;{ }^{* * *} P<0.0001\right.$; Wilcoxon matched paired test or Mann-Whitney test)

microenvironment have not yet been conducted. Our analysis on the immune kinetics found an increasingly dysfunctional $\mathrm{CD}^{+} \mathrm{T}$ cell compartment in progressing patients that was not observed in those patients that remained asymptomatic. Moreover, we showed that soluble factors, such as IL-10 produced by CLL cells, play a role in $\mathrm{CD}^{+} \mathrm{T}$ cell exhaustion and in the progression of the disease.

An altered anti-tumor immune response is evidenced in CLL by diverse factors affecting mainly $\mathrm{T}$ cells $[18-21,31,32]$. Recent studies using the E $\mu$-TCL1 mouse model indicate that $\mathrm{CD}^{+} \mathrm{T}$ cells can delay CLL progression at the same time that their expression of inhibitory receptors progressively increases [50]. Also, although only studied in 3 cases, in spontaneously regressing CLL the expression of PD1 in $\mathrm{CD}^{+} \mathrm{T}$ cells also decreased when malignant cells declined [51]. Accordingly, our longitudinal immune analysis in CLL patients showed that effector memory $\mathrm{CD}^{+} \mathrm{T}$ cell subsets expressing PD1 accumulated specifically at clinical progression. In addition, $\mathrm{EM} \mathrm{CD} 8^{+} \mathrm{T}$ cells co-expressing PD1 with CD244 and CD160 and terminally exhausted (T-bet ${ }^{\mathrm{dim} /}{ }^{-}$Eomes $^{\mathrm{hi}} \mathrm{PD} 1^{\mathrm{hi}}$ ) $\mathrm{CD}^{+}{ }^{+} \mathrm{T}$ cells were significantly increased at progression, denoting severe dysfunction in $\mathrm{CD}^{+} \mathrm{T}$ cells over time. Importantly, these changes were not observed in non-progressing patients, supporting the primary role of immune dysfunction in CLL progression.

Broad analysis of transcriptomic changes also revealed significantly different expression profiles in $\mathrm{T}$ cells at progression compared to diagnosis while only minor differences were found in non-progressing patients along time. Although the low quality of the RNA we obtained hampered a broader analysis, we were able to identify changes in the transcriptome specifically associated with clinical progression when using only uniquely mapped reads to avoid potential artifacts due to low input.

In this study, we also identified that CLL cells obtained at the time of progression had enhanced capacity of inducing exhaustion in both autologous and HD-derived $\mathrm{CD}^{+} \mathrm{T}$ cells compared to malignant CLL cells from patients with stable disease, as well as increased capacity to secrete IL-10 upon microenvironmental stimuli. In addition, we found that PD1 upregulation depended mainly on soluble factors. Therefore, although the accumulation of exhausted $\mathrm{CD}^{+} \mathrm{T}$ cells in progressing patients might be merely the consequence of the higher tumoral load characterizing progression in the majority of patients (see Supplementary Table S2 for clinical data), our data showing increased in vitro capacity to induce $\mathrm{T}$ cell exhaustion and to produce IL-10 are compatible with an scenario where accumulating malignant cells also acquire higher immunosuppressive properties along the course of the disease only in patients that will eventually progress. These cells would then promote engagement in a positive feed-back system further increasing $\mathrm{CD}^{+} \mathrm{T}$ cell exhaustion and ultimately facilitating the transition to clinical progression. In this regard, Gonnord et al. recently described that $\mathrm{CD}^{+} \mathrm{T}$ cells from untreated CLL patients that will need therapy within 6 months after analysis display an unique signature which is not correlated with the time that $\mathrm{CD}^{+} \mathrm{T}$ cells have been exposed to CLL cells [52], indicating again that the exhaustion of $\mathrm{T}$ cells is not a mere product of increased exposure to malignant cells, either in time or in tumoral load. Further studies trying to definitively figure out the mechanisms behind the coevolution of the immune system and malignant cells in CLL are definitively worth performing.

Our results provide pre-clinical evidence to support the design of clinical studies aimed at improving antitumoral $\mathrm{T}$ cell responses. This may be particularly advantageous in the context of treatment with autologous chimeric antigen receptor (CAR)- $\mathrm{T}$ cells derived from patients in an advanced disease stage, which display low cytotoxic activity and achieve low response rates [53]. Notably, immunomodulatory effects of ibrutinib therapy are able to recover $\mathrm{T}$ cell function and subsequently 
increase the response rate to CAR-T cell therapy $[54,55]$. Moreover, these results lay the foundations for the clinical testing of immunotherapy in early stages of the disease to prevent or delay clinical progression. In addition, the identification of signs of increased immunosuppression could be exploited in the future to improve early detection of patients that will likely progress.

\section{Conclusions}

Collectively, our findings indicate that at clinical progression CLL cells exhibit limited genetic changes from diagnosis, while $\mathrm{CD}^{+} \mathrm{T}$ cells show increased exhaustion that can be induced by IL- 10 secreted by malignant B cells. In contrast, patients that remain stable over time did not experience significant changes in their genetic or $\mathrm{T}$ cell compartments. Also, malignant cells from patients at clinical progression showed enhanced capacity to induce exhaustion-related features in $\mathrm{CD}^{+} \mathrm{T}$ cells ex vivo.

These results provide evidence to support the exploration of immunotherapeutic interventions in early stages aiming at avoiding or delaying clinical progression of the disease. Additionally, further analysis of both immunological and malignant B-CLL cell-intrinsic factors in larger cohorts of patients will help us better identify those patients that are more likely to progress shortly after diagnosis.

\section{Abbreviations}

CAR: chimeric antigen receptor; CCF: cancer cell fraction; Cl: confidence interval; CLL: chronic lymphocytic leukemia; CNV: copy number variation; IWCLL: international workshop on CLL; MDSC: myeloid-derived suppressor cells; PBMCs: peripheral blood mononuclear cells; RNA-seq: RNA sequencing; SEM: standard error of the mean; TTP: time to progression; VAF: variant allele fraction; WES: whole exome sequencing

\section{Supplementary Information}

The online version contains supplementary material available at https:/doi. org/10.1186/s40364-021-00290-z.

\section{Additional file 1: Supplementary Table S2. Detailed clinical characteristics from CLL patients. Supplementary Table S3. SNVs and Indels analysis by WES in progressing CLL patients. Supplementary Table S4. CLL driver gene analysis (TP53, BIRC3, ATM, NOTCH1, SF3B1, XPO1, MYD88, FBXW7 and POT1) by NGS in progressing and non- progressing CLL patients. Supplementary Table S5. CNVs analysis by WES in progressing CLL patients. Supplementary Table S6. Differen- tially expressed genes in T cells from CLL patients.}

Additional file 2: Supplementary Table S1. Monoclonal antibodies (mAbs). Supplementary Table S7. Highlighted dysregulated genes in TCLL cells at progression. Supplementary Figure S1. Longitudinal analysis of the CCF of CNVs from paired B-CLL cells at diagnosis and progression before treatment. Comparison of the CCF with $95 \% \mathrm{Cl}$ for each CNV detected per patient $(n=10)$ between diagnosis and progression. Significantly increased (red lines) and stable CCF (grey lines) are shown. Recurrent CNVs in CLL (del(13q), del(11q), del(17p) and $+[12]$ ) are plotted with bold lines and labeled with CNV name: stable CCF (bold black) is shown. Supplementary Figure S2. $C D 8^{+} T$ cell differentiation subsets and PD1 expression in $\mathrm{CD}^{+} \mathrm{T}$ cells from progressing and nonprogressing CLL patients. a CD4/CD8 ratio in progressing $(n=19)$ and non-progressing patients $(n=10)$ at diagnosis and progression or nonprogression. $\mathbf{b}$ Absolute numbers of $\mathrm{CD} 8^{+} \mathrm{T}$ cell differentiation subsets (naive: $\mathrm{CCR}^{+} \mathrm{CD}^{2} 5 \mathrm{RA}^{+}$; central memory, $\mathrm{CM}$ : CCR7 ${ }^{+} \mathrm{CD} 45 \mathrm{RA}^{-}$; effector memory, EM: CCR7 ${ }^{-} \mathrm{CD}_{45 \mathrm{RA}^{-}}$and EM CD45RA ${ }^{+}$, EMRA: CCR7 ${ }^{-} \mathrm{CD} 45 \mathrm{RA}^{+}$) in progressing $(n=19)$ and non-progressing patients $(n=10)$ at diagnosis and progression or non-progression. $\mathbf{c}$ Absolute numbers of $\mathrm{PD} 1^{+} \mathrm{CD}^{+} \mathrm{T}$ cells in progressing (left, $n=19$ ) and non-progressing patients (middle, $n=10$ ) at diagnosis and progression or non-progression. Fold change of $\mathrm{PD} 1{ }^{+} \mathrm{CD}^{+} \mathrm{T}$ cells between time points comparing progressing and nonprogressing patients (right). d Percentage of $\mathrm{PD} 1^{+} \mathrm{CD} 244^{+} \mathrm{CD} 8^{+} \mathrm{T}$ cells in progressing (left, $n=12$ ) and non-progressing patients (middle, $n=9$ ) at diagnosis and progression or non-progression. Fold change of $\mathrm{PD} 1^{+} \mathrm{CD} 244^{+} \mathrm{CD}^{+} \mathrm{T}$ cells between time points comparing progressing and non-progressing patients (right). e Percentage of PD $1^{+} 160^{+} \mathrm{CD}^{+} \mathrm{T}$ cells in progressing (left, $n=12$ ) and non-progressing patients (middle, $n=9$ ) at diagnosis and progression or non-progression. Fold change of $\mathrm{PD} 1^{+} \mathrm{CD} 160^{+} \mathrm{CD} 8^{+} \mathrm{T}$ cells between time points comparing progressing and non-progressing patients (right). f Density plots of PD1, CD160 and CD244 coexpression in CD8 ${ }^{+} \mathrm{T}$ cells in representative patients at diagnosis and progression and at diagnosis and non-progression. Graphs show mean \pm SEM or paired values $\left({ }^{*} P<0.05\right.$; ${ }^{* *} P<0.01$; ${ }^{* *} P<0.001$; Wilcoxon matched paired test or Mann-Whitney test). Supplementary Figure $\mathbf{S 3}$. Flow cytometric analysis of progenitor and terminal $C D 8^{+}$subsets. Gating strategy followed for the identification of T-bet ${ }^{\text {hi }}$ Eomes ${ }^{\text {dim/ }}{ }^{-}$PD ${ }^{\text {mid }}$ and Tbet ${ }^{\text {dim/-E}}$ Eomes ${ }^{\text {hi }} \mathrm{PD} 1^{\text {hi }} \mathrm{CD} 8^{+}$populations. Supplementary Figure S4. Co-expression of PD1 and CD244 in CD8 ${ }^{+} \mathrm{T}$ cells after co-culture with BCLL cells. MDSCs in progressing and non-progressing CLL patients. a Percentages of $\mathrm{PD} 1^{+} \mathrm{CD} 244^{+}$cells out of $\mathrm{CD} 8^{+} \mathrm{T}$ cells from progressing (left) and non-progressing (right) CLL patients after stimulation with anti-CD3 and anti-CD28 for 7 days (grey dots) and in presence of B-HD cells (yellow dots) or B-CLL cells at the time of progression (red dots, $n=10$ ) or asymptomatic follow-up (blue dots, $n=7$ ) at the indicated T:B ratios. b Percentages of $\mathrm{PD}^{+}{ }^{+} \mathrm{CD} 244^{+}$cells out of $\mathrm{CD} 8^{+} \mathrm{T}$ cells from healthy agematched donors (T-HD) after stimulation with anti-CD3 and anti-CD28 for 7 days (grey dots) and in presence of B-CLL cells at progression (bold red dots) or B-CLL cells at asymptomatic follow-up (bold blue dots) at the indicated T:B ratios. $\mathbf{c}$ Percentages of $\mathrm{CD} 8^{+} \mathrm{T}$ cells from CLL patients COexpressing PD1 and CD244 after stimulation with anti-CD3 and anti-CD28 for 7 days and in contact with B-CLL cells or separated by transwell inserts at 1:10 T:B ratio for 7 days $(n=14)$.d Dot plots of $\mathrm{IL}-10^{+} \mathrm{B}$ cells gated on $\mathrm{CD}_{1} 9^{+} \mathrm{CD}^{+}$cells after $5 \mathrm{~h}$ of leukocyte stimulation (PIB), or brefeldin $\mathrm{A}$ (BFA) as control, from one representative patient from the progressed and non-progressed groups respectively. e Percentage of MDSCs $\left(\mathrm{CD} 14^{+} \mathrm{HLA}\right.$-DR ${ }^{\text {low/ }}-$ ) out of $\mathrm{CD} 14^{+}$cells in progressing (left, $n=17$ ) and non-progressing patients (middle, $n=10$ ) at diagnosis and progression or non-progression. Increment of MDSCs between time points comparing progressing and non-progressing patients (right). Graphs show mean \pm SEM or paired values $\left({ }^{*} P<0.05 ;{ }^{* *} P<0.01 ;{ }^{* * *} P<0.001\right.$; ${ }^{* * *} P<0.0001$; Wilcoxon matched paired test or Mann-Whitney test).

\section{Acknowledgements}

The authors thank the patients and healthy donors for their blood donations. The authors also thank the Cellex Foundation for providing research facilities and equipment and the CERCA Programme / Generalitat de Catalunya for institutional support.

\section{Authors's contributions}

I.J., M.C. and F.B. designed reseach; I.J., B.T-V., J.C.N., J.C., M.M., L.P. and C.F-J. performed research; I.J., B.T-V., M.C. and F.B. analyzed and interpreted data; P.A., S.B., J.C.N., C.P-G., R.V-M., A.E-C., G.P. and G.I. contributed to data analysis; P.A., S.B., G.I., M.J.T. and J.A.G-M. provided patient samples; M.C. and F.B. supervised the work; I.J., M.C. and F.B. wrote the manuscript; all authors reviewed the manuscript. The author(s) read and approved the final manusript.

\section{Funding}

This work was supported by the Instituto de Salud Carlos III, Fondo de Investigaciones Sanitarias (PI17/00950, M.C., PI18/01392, P.A. and PI17/00943, F.B.) and co-financed by the European Regional Development Fund (ERDF) and Fundación Asociación Española Contra el Cáncer (M.C. and P.A.), Gilead 
Fellowships (GLD16/00144, GLD18/00047, F.B.) and Fundació la Marató de TV3 (201905-30-31 F.B). S.B. is the recipient of a postdoctoral fellowship from Fundación Alfonso Martin Escudero. R.V-M. is supported by a Torres Quevedo fellowship from the Spanish Ministry of Science and Innovation (PTQ-1608623). A.E-C. is funded by ISCIII/MINECO (PT17/0009/0019) which is cofunded by FEDER. M.C. holds a contract from Ministerio de Ciencia, Innovación y Universidades (RYC-2012-2018).

\section{Availability of data and materials}

For original data, please contact the corresponding author. WES and RNASeq data generated during the current study are deposited at EGA and GEO under accession numbers EGAS00001004116 and GSE141787, respectively.

\section{Declarations}

\section{Ethics approval and consent to participate}

A written informed consent was obtained from all individuals in accordance with the declaration of Helsinki and the study was approved by the clinical research ethics committee at Vall d'Hebron Hospital Universitari.

\section{Consent for publication}

Not applicable.

\section{Competing interests}

P.A. has received honoraria from Janssen, Roche, Celgene and AbbVie. G.I. has received honoraria from Celgene, Novartis, Roche, AbbVie, Janssen and Gilead. J.A.G-M. has received research funding and honoraria from Roche, Janssen and AbbVie. M.C. has received research funding from, Pharmacyclics, Roche, ArQule and AstraZeneca. F.B. has received research funding and honoraria from Roche, Celgene, Takeda, AstraZeneca, Novartis, AbbVie and Janssen. All remaining authors have declared no conflicts of interest.

\section{Author details}

'Experimental Hematology, Vall d'Hebron Institute of Oncology (VHIO), Vall d'Hebron Barcelona Hospital Campus, C/Natzaret 115-117, 08035 Barcelona, Spain. ${ }^{2}$ Department de Medicina, Universitat Autònoma de Barcelona, 08193 Bellaterra, Spain. ${ }^{3}$ Servei d'Hematologia, Vall d'Hebron Hospital Universitari, Experimental Hematology, Vall d'Hebron Institute of Oncology (VHIO), Vall d'Hebron Barcelona Hospital Campus, Passeig Vall d'Hebron 119-129, 08035 Barcelona, Spain. ${ }^{4}$ DREAMgenics, 33011 Oviedo, Spain. ${ }^{5}$ Centre for Genomic Regulation, Barcelona Institute of Science and Technology, 08003 Barcelona, Spain. ${ }^{6}$ Universitat Pompeu Fabra, 08002 Barcelona, Spain. ${ }^{7}$ Servei d'Immunologia, Vall d'Hebron Institut de Recerca (VHIR), Vall d'Hebron Hospital Universitari, Vall d'Hebron Barcelona Hospital Campus, Passeig Vall d'Hebron 119-129, 08035 Barcelona, Spain. ${ }^{8}$ Department of Hematology, Clínic University Hospital, INCLIVA Biomedical Research Institute, 46010 Valencia, Spain. ${ }^{9}$ Department of Hematology, Puerta de Hierro University Hospital, 28222, Majadahonda, Madrid, Spain.

Received: 2 December 2020 Accepted: 26 April 2021 Published online: 20 May 2021

\section{References}

1. Hamblin TJ, Davis Z, Gardiner A, Oscier DG, Stevenson FK. Unmutated Ig $V(H)$ genes are associated with a more aggressive form of chronic lymphocytic leukemia. Blood. 1999;94(6):1848-54. https://doi.org/10.1182/ blood.V94.6.1848.

2. Crespo M, Bosch F, Villamor N, Bellosillo B, Colomer D, Rozman M, et al. ZAP-70 expression as a surrogate for immunoglobulin-variable-region mutations in chronic lymphocytic leukemia. N Engl J Med. 2003;348(18): 1764-75. https://doi.org/10.1056/NEJMoa023143.

3. Döhner $H$, Stilgenbauer $S$, Benner A, Leupolt E, Kröber A, Bullinger $L$, et al. Genomic aberrations and survival in chronic lymphocytic leukemia. N Engl Med. 2000;343(26):1910-6. https://doi.org/10.1056/NEJM200012283432602.

4. Bosch F, Dalla-Favera R. Chronic lymphocytic leukaemia: from genetics to treatment. Nat Rev Clin Oncol. 2019;16(11):684-701.

5. International CLL-IPI working group. An international prognostic index for patients with chronic lymphocytic leukaemia (CLL-IPI): a metaanalysis of individual patient data. Lancet Oncol. 2016;17(6):779-90. https://doi.org/10.1 016/S1470-2045(16)30029-8. Epub 2016 May 13.
6. Stilgenbauer S, Sander S, Bullinger L, Benner A, Leupolt E, Winkler D, et al. Clonal evolution in chronic lymphocytic leukemia: acquisition of high-risk genomic aberrations associated with unmutated $\mathrm{VH}$, resistance to therapy, and short survival. Haematologica. 2007;92(9):1242-5. https://doi.org/1 0.3324/haematol.10720.

7. Gunnarsson R, Mansouri L, Isaksson A, Goransson H, Cahill N, Jansson M, et al. Array-based genomic screening at diagnosis and during follow-up in chronic lymphocytic leukemia. Haematologica. 2011;96(8):1161-9. https:// doi.org/10.3324/haematol.2010.039768.

8. Landau DA, Carter SL, Stojanov P, McKenna A, Stevenson K, Lawrence MS, et al. Evolution and impact of subclonal mutations in chronic lymphocytic leukemia. Cell. 2013;152(4):714-26. https://doi.org/10.1016/j. cell.2013.01.019.

9. Nadeu F, Delgado J, Royo C, Baumann T, Stankovic T, Pinyol M, et al. Clinical impact of clonal and subclonal TP53, SF3B1, BIRC3, NOTCH1, and ATM mutations in chronic lymphocytic leukemia. Blood. 2016;127(17):2122-30. https://doi.org/10.1182/blood-2015-07-659144.

10. Rose-Zerilli MJJ, Gibson J, Wang J, Tapper W, Davis Z, Parker H, et al. Longitudinal copy number, whole exome and targeted deep sequencing of "good risk" IGHV-mutated CLL patients with progressive disease. Leukemia. 2016;30(6):1301-10. https://doi.org/10.1038/leu.2016.10.

11. Smith EN, Ghia EM, DeBoever CM, Rassenti LZ, Jepsen K, Yoon K-A, et al. Genetic and epigenetic profiling of CLL disease progression reveals limited somatic evolution and suggests a relationship to memory-cell development. Blood Cancer J. 2015;5(4):e303. https://doi.org/10.1038/bcj.2015.14.

12. Hernández-Sánchez M, Kotaskova J, Rodríguez AE, Radova L, Tamborero D, Abáigar $M$, et al. CLL cells cumulate genetic aberrations prior to the first therapy even in outwardly inactive disease phase. Leukemia. 2019;33(2):51858.

13. Gruber M, Bozic I, Leshchiner I, Livitz D, Stevenson K, Rassenti L, et al. Growth dynamics in naturally progressing chronic lymphocytic leukaemia. Nature. 2019;570(7762):474-9. https://doi.org/10.1038/s41586-019-1252-x.

14. Leeksma AC, Taylor J, Wu B, Gardner JR, He J, Nahas M, et al. Clonal diversity predicts adverse outcome in chronic lymphocytic leukemia. Leukemia. 2019; 33(2):390-402. https://doi.org/10.1038/s41375-018-0215-9.

15. Ramassone A, D'Argenio A, Veronese A, Basti A, Soliman SHA, Volinia S, et al. Genetic dynamics in untreated CLL patients with either stable or progressive disease: a longitudinal study. J Hematol Oncol. 2019;12(1):114. https://doi.org/10.1186/s13045-019-0802-x.

16. Fernandez V, Jares P, Salaverria I, Gine E, Bea S, Aymerich M, et al. Gene expression profile and genomic changes in disease progression of earlystage chronic lymphocytic leukemia. Haematologica. 2008;93(1):132-6. https://doi.org/10.3324/haematol.11694.

17. Riches JC, Gribben JG. Immunomodulation and immune reconstitution in chronic lymphocytic leukemia. Semin Hematol. 2014;51(3):228-34. https:// doi.org/10.1053/j.seminhematol.2014.05.006.

18. Riches JC, Davies JK, McClanahan F, Fatah R, labal S, Agrawal S, et al. T cells from CLL patients exhibit features of T-cell exhaustion but retain capacity for cytokine production. Blood. 2013;121(9):1612-21. https://doi.org/10.1182/ blood-2012-09-457531.

19. Ramsay AG, Johnson AJ, Lee AM, Gorgün G, Le Dieu R, Blum W, et al. Chronic lymphocytic leukemia T cells show impaired immunological synapse formation that can be reversed with an immunomodulating drug. J Clin Invest. 2008;118(7):2427-37. https://doi.org/10.1172/JCl35017.

20. Ramsay AG, Clear AJ, Fatah R, Gribben JG. Multiple inhibitory ligands induce impaired T-cell immunologic synapse function in chronic lymphocytic leukemia that can be blocked with lenalidomide: establishing a reversible immune evasion mechanism in human cancer. Blood. 2012;120(7):1412-21. https://doi.org/10.1182/blood-2012-02-411678.

21. Palma M, Gentilcore G, Heimersson K, Mozaffari F, Näsman-Glaser B, Young E, et al. T cells in chronic lymphocytic leukemia display dysregulated expression of immune checkpoints and activation markers. Haematologica. 2017;102(3):562-72. https://doi.org/10.3324/haematol.2016.151100.

22. Nunes C, Wong R, Mason M, Fegan C, Man S, Pepper C. Expansion of a CD8(+ PPD-1(+) replicative senescence phenotype in early stage CLL patients is associated with inverted CD4:CD8 ratios and disease progression. Clin Cancer Res. 2012;18(3):678-87. https://doi.org/10.1158/1078-0432.CCR-11-2630.

23. Jitschin R, Braun M, Buttner M, Dettmer-Wilde K, Bricks J, Berger J, et al. CLLcells induce IDOhi CD14+HLA-DRlo myeloid-derived suppressor cells that inhibit T-cell responses and promote TRegs. Blood. 2014;124(5):750-60. https://doi.org/10.1182/blood-2013-12-546416. 
24. DiLillo DJ, Weinberg JB, Yoshizaki A, Horikawa M, Bryant JM, Iwata Y, et al. Chronic lymphocytic leukemia and regulatory B cells share IL-10 competence and immunosuppressive function. Leukemia. 2013;27(1):17082. https://doi.org/10.1038/leu.2012.165.

25. Valdés-Mas R, Bea S, Puente DA, López-Otín C, Puente XS. Estimation of copy number alterations from exome sequencing data. PLoS One. 2012; 7(12):e51422. https://doi.org/10.1371/journal.pone.0051422.

26. Shinde J, Bayard Q, Imbeaud S, Hirsch TZ, Liu F, Renault V, et al. Palimpsest: an $\mathrm{R}$ package for studying mutational and structural variant signatures along clonal evolution in cancer. Bioinformatics. 2018;34(19):3380-1.

27. Purroy N, Abrisqueta P, Carabia J, Carpio C, Calpe E, Palacio C, et al. Targeting the proliferative and chemoresistant compartment in chronic lymphocytic leukemia by inhibiting survivin protein. Leukemia. 2014;28(10): 1993-2004. https://doi.org/10.1038/leu.2014.96.

28. Hallek M, Cheson BD, Catovsky D, Caligaris-Cappio F, Dighiero G, Döhner H, et al. iwCLL guidelines for diagnosis, indications for treatment, response assessment, and supportive management of CLL. Blood. 2018;131(25):274560. https://doi.org/10.1182/blood-2017-09-806398.

29. Landau DA, Tausch E, Taylor-Weiner AN, Stewart C, Reiter JG, Bahlo J, et al. Mutations driving CLL and their evolution in progression and relapse. Nature. 2015;526(7574):525-30. https://doi.org/10.1038/nature15395.

30. Gonzalez-Perez A, Perez-Llamas C, Deu-Pons J, Tamborero D, Schroeder MP, Jene-Sanz A, et al. IntOGen-mutations identifies cancer drivers across tumor types. Nat Methods. 2013;10(11):1081-2. https://doi.org/10.1038/nmeth.2642.

31. Mackus WJM, Frakking FNJ, Grummels A, Gamadia LE, De Bree GJ, Hamann D, et al. Expansion of CMV-specific CD8+CD45RA+CD27- T cells in B-cell chronic lymphocytic leukemia. Blood. 2003;102(3):1057-63. https://doi.org/1 0.1182/blood-2003-01-0182.

32. Brusa D, Serra S, Coscia M, Rossi D, D'Arena G, Laurenti L, et al. The PD-1/ PD-L1 axis contributes to T-cell dysfunction in chronic lymphocytic leukemia. Haematologica. 2013;98(6):953-63. https://doi.org/10.3324/haema tol.2012.077537.

33. Gros A, Robbins PF, Yao X, Li YF, Turcotte S, Tran E, et al. PD-1 identifies the patient-specific CD8(+) tumor-reactive repertoire infiltrating human tumors. J Clin Invest. 2014;124(5):2246-59. https://doi.org/10.1172/JCI73639.

34. Ahmadzadeh $M$, Johnson LA, Heemskerk B, Wunderlich JR, Dudley ME, White DE, et al. Tumor antigen-specific CD8 T cells infiltrating the tumor express high levels of PD-1 and are functionally impaired. Blood. 2009; 114(8):1537-44. https://doi.org/10.1182/blood-2008-12-195792.

35. Blackburn SD, Shin H, Haining WN, Zou T, Workman CJ, Polley A, et al. Coregulation of CD8+ T cell exhaustion by multiple inhibitory receptors during chronic viral infection. Nat Immunol. 2009;10(1):29-37. https://doi. org/10.1038/ni.1679.

36. Intlekofer AM, Takemoto N, Wherry EJ, Longworth SA, Northrup JT, Palanivel VR, et al. Effector and memory CD8+ T cell fate coupled by T-bet and eomesodermin. Nat Immunol. 2005;6(12):1236-44. https://doi.org/10.1038/ni1268.

37. Kao C, Oestreich KJ, Paley MA, Crawford A, Angelosanto JM, Ali MA, et al. Transcription factor T-bet represses expression of the inhibitory receptor PD-1 and sustains virus-specific CD8+ T cell responses during chronic infection. Nat Immunol. 2011;12(7):663-71. https://doi.org/10.1038/ni.2046.

38. Paley MA, Kroy DC, Odorizzi PM, Johnnidis JB, Dolfi DV, Barnett BE, et al. Progenitor and terminal subsets of CD8+ T cells cooperate to contain chronic viral infection. Science. 2012;338(6111):1220-5. https://doi.org/1 $0.1126 /$ science.1229620.

39. Pauken KE, Wherry EJ. Overcoming T cell exhaustion in infection and cancer. Trends Immunol. 2015;36(4):265-76. https://doi.org/10.1016/j.it.2015. 02.008 .

40. Llaó-Cid L, Roessner PM, Chapaprieta V, Öztürk S, Roider T, Bordas M, et al. EOMES is essential for antitumor activity of CD $8+T$ cells in chronic lymphocytic leukemia. Leukemia. 2021;17:1-11.

41. Thommen DS, Schumacher TN. T Cell Dysfunction in Cancer. Cancer Cell. 2018;33(4):547-62.

42. Best JA, Blair DA, Knell J, Yang E, Mayya V, Doedens A, et al. Transcriptional insights into the CD8(+) T cell response to infection and memory $T$ cell formation. Nat Immunol. 2013;14(4):404-12. https://doi.org/10.1038/ni.2536.

43. Schoggins JW, Wilson SJ, Panis M, Murphy MY, Jones CT, Bieniasz P, et al. A diverse range of gene products are effectors of the type I interferon antiviral response. Nature. 2011;472(7344):481-5. https://doi.org/10.1038/na ture09907.

44. Schietinger A, Philip M, Krisnawan VE, Chiu EY, Delrow JJ, Basom RS, et al. Tumor-Specific T Cell Dysfunction Is a Dynamic Antigen-Driven
Differentiation Program Initiated Early during Tumorigenesis. Immunity. 2016:45(2):389-401.

45. Alhakeem SS, McKenna MK, Oben KZ, Noothi SK, Rivas JR, Hildebrandt GC, et al. Chronic lymphocytic leukemia-derived IL-10 suppresses antitumor immunity. J Immunol. 2018;200(12):4180-9. https://doi.org/10.4049/ jimmunol.1800241.

46. Drennan S, D'Avola A, Gao Y, Weigel C, Chrysostomou E, Steele AJ, et al. IL10 production by CLL cells is enhanced in the anergic IGHV mutated subset and associates with reduced DNA methylation of the IL10 locus. Leukemia. 2017;31(8):1686-94. https://doi.org/10.1038/leu.2016.356.

47. Fayad L, Keating MJ, Reuben JM, O'Brien S, Lee BN, Lerner S, et al. Interleukin-6 and interleukin-10 levels in chronic lymphocytic leukemia: correlation with phenotypic characteristics and outcome. Blood. 2001;97(1): 256-63. https://doi.org/10.1182/blood.V97.1.256.

48. Thommen DS, Koelzer VH, Herzig P, Roller A, Trefny M, Dimeloe S, et al. A transcriptionally and functionally distinct PD-1 + CD8 + T cell pool with predictive potential in non-small-cell lung cancer treated with PD-1 blockade. Nat Med. 2018;24(7):994-1004. https://doi.org/10.1038/s41591-01 8-0057-z.

49. Azzaoui I, Uhel F, Rossille D, Pangault C, Dulong J, Priol JL, et al. T-cell defect in diffuse large B-cell lymphomas involves expansion of myeloid-derived suppressor cells. Blood. 2016;128(8):1081-92. https://doi.org/10.1182/blood-2 015-08-662783.

50. Hanna BS, Roessner PM, Yazdanparast H, Colomer D, Campo E, Kugler S, et al. Control of chronic lymphocytic leukemia development by clonallyexpanded CD8+ T-cells that undergo functional exhaustion in secondary lymphoid tissues. Leukemia. 2019;33(3):625-37.

51. Kwok M, Oldreive C, Rawstron AC, Goel A, Papatzikas G, Jones RE, et al. Integrative analysis of spontaneous CLL regression highlights genetic and microenvironmental interdependency in CLL. Blood. 2020;135(6):411-28.

52. Gonnord P, Costa M, Abreu A, Peres M, Ysebaert L, Gadat S, et al. Multiparametric analysis of CD8+ T cell compartment phenotype in chronic lymphocytic leukemia reveals a signature associated with progression toward therapy. Oncoimmunology. 2019;8(4):e1570774. Available from: https://www.ncbi.n/m.nih.gov/pmc/articles/PMC6422371/.

53. Porter DL, Hwang W-T, Frey NV, Lacey SF, Shaw PA, Loren AW, et al. Chimeric antigen receptor $T$ cells persist and induce sustained remissions in relapsed refractory chronic lymphocytic leukemia. Sci Transl Med. 2015; 7(303):303ra139.

54. Gill SI, Vides V, Frey NV, Metzger S, O'Brien M, Hexner E, et al. Prospective clinical trial of anti-CD19 CAR T cells in combination with Ibrutinib for the treatment of chronic lymphocytic leukemia shows a high response rate. Blood. 2018;132(Suppl 1):298-8. https://doi.org/10.11 82/blood-2018-99-115418

55. Gauthier J, Hirayama AV, Hay KA, Li D, Lymp J, Sheih A, et al. Comparison of efficacy and toxicity of CD19-specific chimeric antigen receptor T-cells alone or in combination with Ibrutinib for relapsed and/or refractory CLL. Blood. 2018;132(Suppl 1):299-9. https://doi.org/10.1182/blood-2018-99-111061.

\section{Publisher's Note}

Springer Nature remains neutral with regard to jurisdictional claims in published maps and institutional affiliations.

Ready to submit your research? Choose BMC and benefit from:

- fast, convenient online submission

- thorough peer review by experienced researchers in your field

- rapid publication on acceptance

- support for research data, including large and complex data types

- gold Open Access which fosters wider collaboration and increased citations

- maximum visibility for your research: over $100 \mathrm{M}$ website views per year

At $\mathrm{BMC}$, research is always in progress.

Learn more biomedcentral.com/submissions 